Original article

\title{
Socio-environmental conflicts between the refugee populations and their host communities: The case of Eritrean Refugees in North Western Tigray, Ethiopia
}

\author{
Mekonen Aregai $^{1 *}$, Muluberhan Bedemariam² \\ ${ }^{1}$ Department of Soil Resource and Water Shade Management, Aksum University, Shire campus, P.O.Box 314, Shire, Tigray, \\ Ethiopia \\ ${ }^{2}$ Department of Soil Resource and Water Shade Management, College of Agriculture, Aksum University, Shire campus, P.O.Box \\ 314, Shire, Tigray, Ethiopia \\ E-mail address ( ${ }^{*}$ corresponding author): mekonen2001@gmail.com \\ ORCID iD: Mekonen Aregai:: https://orcid.org/0000-0002-2261-0518; Muluberhan Bedemariam: https://orcid.org/0000-0002- \\ 4778-6640
}

\begin{abstract}
This article presents research on the socio environmental impact of refugees on their host communities. We assessed the challenges of refuge populations to their host community in north western Tigray, Ethiopia, where the Eritrean refugees are settled,. Primary data was produced from semi-structured questionnaires and a random sampling technique deploying a logistic regression model to describe the relationship between the socio-environmental changes of the host community. Results suggested $96 \%$ of the sample respondents confirmed changes of tree species and forest coverage on community farms was observed during the study period. Similarly, change in forest coverage and changes in tree species are strongly and positively associated with the existence of refugees in the study communities. The dramatic change observed on forest coverage and tree species has led to a progressive decline in natural resources. The study concluded that unplanned human population influxes, especially refugee inflows, affected host communities negatively and the socio-environmental situation has been significantly changed in the study areas. The study highlights the need for holistic intervention to ameliorate the negative impacts and to maintain the sustainable management of natural resources so as to improve the socio-environmental impact of refugees on host communities.
\end{abstract}

KEY WORDS: socio-environment; logistic regression; impact of Eritrean refugees; North Western Tigray, Ethiopia

ARTICLE HISTORY: received 19 February 2020; received in revised form 22 May 2020; accepted 26 May 2020

\section{Introduction}

The refugee populations from Eritrea have appeared in north western Tigray, Ethiopia, in different refugee camps established in various seasons since 2004. As Ethiopia is receiving large numbers of refugees who are from neighboring and other countries from different directions (BIRHANU \& DESTA, 2018), the existence of new populations has led to an increase in socio-environmental conflicts which have brought about a high demand for space, energy and a change in environmental quality. The high concentration of people per land area obviously aggravates the human impact on the environment. The world experiences shows that a massive and rapid influx of refugees poses security, economic and environmental threats to countries (DE HAAS, 2012). Research evidences proved that human activities have altered climatic patterns by influencing plant cover and other environmental factors (EVANS, 2010). The changes in the relative abundance of local resources to one of acute scarcity can occur because of a largescale and sudden influx of refugees (UNEP, 2011). On the other hand, evenly spread smaller groups throughout the receiving area impose less intense 
impacts and enable to lessen the human impact for a better ecological recovery rates (BLUNDELL ET AL., 2011). The concerns of human impact and the disputes emanated from the refugee flows have gained more attention due to a continued increase in conflicts in many parts of the world (CRUSH ET AL., 2017). Additionally, the overall movement of humans where a new population with is a huge influx of refugees often means more competition for limited resources, which may lead to the host population becoming more destitute than they were initially (UNHCR, 2011). The current issue of massive refugee influxes continues to make research on refugee impacts on host nations a necessity (OMATA \& WEAVER, 2015).

The environment has its implications on the livelihood of the host community and the refugee population and in most cases the area undergoes environmental changes due to the pressure induced by these human population influxes. As (IDMC, 2014) noted, that there is high refugee influx which is unplanned and unpredictable. The increasing refuge influx and in a such circumstances it is very important to note that using more research out comes on the current issues is needed to increase our understanding of the changes and consequences of the effects of refugees on their host communities (BILGILI, 2018). The implications of refugee settlements in the study areas obtained from data analyses illustrates that there exists high rates of exploitation of forests and a decline in their coverage with the growing perception of the host community that the observed changes in the nature of rainfall and temperature resulting from depletion of forests. Unwise use of forest resources which may cause deforestation is among the most big problems and most frequently mentioned environmental impact of refugee settlement areas which in otherwise affect the refugee hosting countries (WILSON, 2014).

From the point of economic arguments, increasingly hosting significant numbers of refugees has both economic and social impacts for the host community (OECD, 2017). Challenges especially beyond the tolerance level of the host community is true with unpredicted losses and is common for most developing countries, where the structures for aggregating the economic activities of the displaced refuges are predominantly influence the host community (TAYLOR ET AL., 2016a). The magnitude of unprecedented flows in recent years has produced concerns for the potential threat to the social and economic stability of the host states (KIRUI \& MWARUVIE, 2012). The imbalances which have been created because of the situation have emanated from new settlers from the neighbouring country of Eritrea because of the political instability in the nation, and the host community remains desperate as the number of refugees is increasing considerably. In areas, where refugee populations have settled, the livelihood of host community residents depends on crop and livestock production and the impact of the refugee population ranges from deforestation to declining agricultural production and losses of biodiversity. The impact of hosting refugees falls most heavily on developing countries, since the highest refuge concentrations are in some of the poorest countries in the world (UNHCR, 2003). It is important to recognize that the negative impact of refugee inflows generally has been distinguished as environmental and socio-economic problems in the host countries. (GOMEZ \& CHRISTENSEN, 2010). Countries which border Ethiopia are facing political, social, economic and environmental challenges and this has led to substantial increase in refugees (BIRHANU \& DESTA, 2018). Since 2014 a total of 58,000 people from 13 countries have become refugees in Ethiopia, the majority were from Somalia, South Sudan and Eritrea (about 94,000 were from Eritrea) (NRC, 2014). The largest number of the Eritrean refugee populations are settled in places within the north western Tigray, Ethiopia.

The magnitude of the environmental changes which have resulted from the huge presence of refugee populations is becoming a source of conflict in the study area which is deemed to raise issues that require attention in order to minimize the losses. The current tangible documents explains more the impacts of hosting refugees are creating pressure and instability between the host community and refugee populations (ALLOUSH ET AL., 2017). This study sought to investigate the impact of Eritrean refugees on the host communities in north western Tigray, Ethiopia, which have been exhibited in the natural environment following the inception of the refugee settlements. Evidence from the socio-economic and environmental impacts of refugees in forest covered areas with all the natural resources and agricultural products of the area are likely to be impacted (ALIX-GARCIA \& SAAH, 2010). As the new settlement areas were built in areas that were occupied by the host community, the changes usually require more attention to ameliorate the impacts especially for those environmental changes which may require an extended period of time to bring them back to their previous condition. Therefore, the aim of the study was to investigate the socio-environmental impacts of Eritrean refugees on the host communities in the north western zone of Tigray, northern Ethiopia, and was conducted in the year 2018. 


\section{Materials and methods}

\subsection{Study area}

The north west zone of Tigray is located in Tigray regional state, northern Ethiopia. It shares an international boundary with Eritrea to the north (Fig. 1). The zone covers predominantly lowland areas though some areas are mountainous and lay in the midlands. Lowland topography is mainly forest covered in acacia trees. The temperature of the lowland areas of the zone rise to an average of $42^{\circ} \mathrm{C}$ between April and June and fall to between 25 and $35^{\circ} \mathrm{C}$ during the moderate months between July and February. With $14,041.12 \mathrm{~km}^{2}$ coverage, the area has been one of the densely forested areas of Tigray and is a farming area. It is characterized by a mono-modal rainfall ranging from $450-500 \mathrm{~mm}$ annually with an altitude range of $645 \mathrm{~m}$ a.s.l. in the lower valleys to $2852 \mathrm{~m}$ a.s.l. in the high mountainous places of the study area.

The population of the north west zone in 2007 was 736,805 (CSA, 2007) and was estimated to be
995,780 in 2017. Mixed crop-livestock farming is the main livelihood base for the rural communities.

For this study, three Kebelles, namely MayKuhili, Wuhdet and Hitsats where Shimelba, Wuhdet and Hitsats refugee camps respectively were selected. The refugee camps were established in different periods as shown in Table 1 .

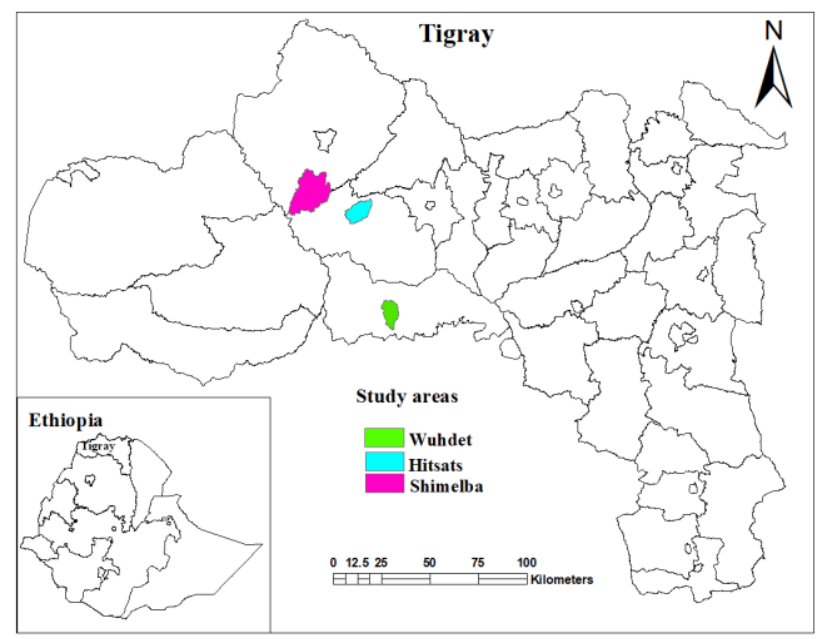

Fig. 1. Location of the study area

Table 1. Refugee camps under study and their year of establishment

\begin{tabular}{|c|l|l|l|l|}
\hline S. No & \multicolumn{1}{|c|}{ Refugee Camp } & \multicolumn{1}{|c|}{ 1Kebelle } & \multicolumn{1}{|c|}{ District } & \multicolumn{1}{|c|}{ (ear establishment } \\
\hline 1 & Shimelba & May kuhili & Tahtay Adyabo & 2004, May \\
\hline 2 & Adiharush & Wuhdet & Tselemti & 2010, March \\
\hline 3 & Hitsats & Hitsats & Asgede Tsimbela & 2013, May \\
\hline
\end{tabular}

${ }^{1}$ Kebelle is the lowest administrative structure with an average 20000 population in the study area

\subsection{Data collection and methods}

A random sampling technique was used to select 192 households equally distributed in the three refugee host community Kebelles for the purpose of analysis. Two sets of questionnaires were prepared based on the information on the area including the camps and related literature (BEINE ET AL. 2016). One for individual respondents, and the other for community leaders, community and district professionals. Questionnaires had different parts consisting of question items and these were semi-structured types of questionnaires. Major points included in the questionnaires were, but not limited to, socio-environmental changes, the related drivers for each change, change in vegetation cover, perception of the residents to climate change particularly rainfall and temperature, and management practices of natural resources. The information from the closed ended questions was analysed using a logistic regression model to identify the socio-environmental impact of refugee populations. A descriptive statistical tool was also used for the qualitative description of the nonquantifiable data from open ended questions. Random sampling of key informants, focus group discussions and field observations were carried out during the data collection period. The focus group discussion was carried out with 120 randomly selected households composed of 8 people in a group led by the researchers to yield a variety of ideas and views regarding the overall status of the refuge population in the study area. Findings from the household survey interviews were interpreted in a disaggregated way and viewed with the focus group results.

\subsection{Model specification}

\subsubsection{Logistic regression model}

A logistic regression model was used to describe the relationship between the socio-environmental changes of the host community as a dependent variable and the observed changes on: tree types, community forest coverage, tree species, rainfall 
and temperature as independent variables to predict the dependent variable. The socioenvironmental determinants of refugee populations on the host community and the expected value of the outcome variable that is given by $E\left(S E C_{i} \mid X_{i}\right)$ where $S E C_{i}$ represents the outcome variable of interest (i.e. the socio-environmental impact of the host community) and $X_{i}$ represents the independent variable.

The basic assumption of the ordinary least square regression method is that the error term should normally be distributed with an expected mean of zero $\left(\mathrm{E}\left(\varepsilon_{i} \mid X_{i}\right)=0\right)$ for all observations and a constant variance $\left(\operatorname{Var}\left(\varepsilon_{i} \mid X_{i}\right)=\mathrm{E}\left(\varepsilon_{i}^{2} \mid X_{i}\right)=\delta_{\varepsilon}^{2}\right)$. This does not hold true when the outcome variable is a binary outcome variable (HOSMER \& LEMESHOW, 2000; WOOLDRIDGE, 2002). The ordinary least square method also assumes constant marginal effects of explanatory variables on the outcome variable. Thus, when the dependent variable is a binary outcome, making use of a binary outcome logistic regression is the most appropriate analytical tool to analyse the obtained data (WOOLDRIDGE, 2002).

Assume there are $\mathrm{N}$ independent sample observations with $S E C_{i}$ representing the binary outcome variable, which has two categories denoted by 1 and 0 . Therefore, in a logistic regression model, the dependent variable $\left(S E C_{i}\right)$ follows a Bernoulli probability function, which takes a value of 1 for the changes due to the refugees' impact on the host community $\left(S E C_{i}=1\right)$ and 0 otherwise $\left(S E C_{i}=0\right)$. The overall model specification for a binary choice model is given by [01]:

$\pi=\operatorname{Pr}\left(S E C_{i}=1 \mid X_{k}\right)=\operatorname{Pr}\left(X_{k}\right)=$

$\mathrm{G}\left(\alpha_{0}+\alpha_{1} X_{1}+\alpha_{2} X_{2}+\ldots+\alpha_{k} X_{k}\right)=G(X \alpha)$ Where:

$-\pi(0 \leq \pi \leq 1)$ is the probability of the outcome of interest;

- G(.) is the normal or logistic commutative distribution function (CDF);

- $X_{i}=\left(X, X_{2}, \ldots X_{k}\right)$ is the vector of independent variables for the $i^{\text {th }}$ observation and;

$-\alpha_{k}$ denotes the vector of unknown parameters.
Therefore, based on equation [01], the conditional probability of the logistic regression equation for the sample respondent $\left(y_{i j}=1\right)$ is given as follows:

$\operatorname{Pr}\left(y_{i j}=1\right)=\operatorname{Pr}\left(S E C_{i}=1 \mid X_{k}\right)=\operatorname{Pr}\left(X_{k}\right)=$
$\left(\frac{\exp \left(\alpha_{0}+\alpha_{1} X_{1}+\alpha_{2} X+\ldots+\alpha_{k} X_{k}\right)}{1+\exp \left(\alpha_{0}+\alpha_{1} X_{1}+\alpha_{2} X_{2}+\ldots+\alpha_{k} X_{k}\right)}\right)$

Equation [02] can be rewritten as follows:

$\operatorname{Pr}\left(y_{i j}=1\right)=\operatorname{Pr}\left(S E C_{i}=1 \mid X_{k}\right)=\operatorname{Pr}\left(X_{k}\right)=$

$\left(\frac{\exp ^{\alpha_{0}}+\sum_{i=1}^{n} \alpha_{k} X_{k}}{1+\exp ^{\alpha_{0}}+\sum_{i=1}^{n} \alpha_{k} X}\right)$

Against the probability of the no-changes of the refugees' impact on the host community, is given by:

$1-\operatorname{Pr}\left(S E C_{i}=1 \mid X_{k}\right)=1-\operatorname{Pr}\left(X_{k}\right)=$

$1-\left(\frac{\exp \left(\alpha_{0}+\alpha_{1} X_{1}+\alpha_{2} X_{2}+\ldots+\alpha_{k} X_{k}\right)}{1+\exp \left(\alpha_{0}+\alpha_{1} X_{1}+\alpha_{2} X_{2}+\ldots+\alpha_{k} X_{k}\right)}\right)$

Thus, to compute the odds the ratio, equation [03] should be divided by equation [04] as follows [05]:

$\left(\frac{\operatorname{Pr}\left(X_{k}\right)}{1-\operatorname{Pr}\left(X_{k}\right)}\right)=\frac{\left(\frac{\exp \left(\alpha_{0}+\alpha_{1} X_{1}+\alpha_{2} X_{2}+\ldots+\alpha_{k} X_{k}\right)}{1+\exp \left(\alpha_{0}+\alpha_{1} X_{1}+\alpha_{2} X_{2}+\ldots+\alpha_{k} X_{k}\right)}\right)}{\left(\frac{1}{1+\exp \left(\alpha_{0}+\alpha_{1} X_{1}+\alpha_{2} X_{2}+\ldots+\alpha_{k} X_{k}\right)}\right)}$

Where:

- $\left(\frac{\operatorname{Pr}\left(X_{k}\right)}{1-\operatorname{Pr}\left(X_{k}\right)}\right)$ is the odds of being the refugees' impact on the host community against no change in the host community.

- The left-hand side of equation [05] is the value of the ratio of probabilities $\left(\frac{\operatorname{Pr}\left(c_{k}\right)}{1-\operatorname{Pr}\left(c_{k}\right)}\right)$ while the right-hand side represents the non-linear function of the independent variables.

- $\alpha_{0}$ and $\alpha_{k}$, respectively denote the intercept and the vector of unknown parameters. An alternative logistic regression can be formed by transforming the equation [05] or the logit transformation by taking its natural $\log (\ln )$. Therefore, the logarithmic transformation of the estimated logistic regression model can be rewritten as follows:

$\operatorname{In}\left(\frac{\operatorname{Pr}\left(X_{k}\right)}{1-\operatorname{Pr}\left(X_{k}\right)}\right)=\operatorname{In}\left\{\frac{\left(\frac{\exp \left(\alpha_{0}+\alpha_{1} X_{1}+\alpha_{2} X_{2}+\ldots+\alpha_{k} X_{k}\right)}{1+\exp \left(\alpha_{0}+\alpha_{1} X_{1}+\alpha_{2} X_{2}+\ldots+\alpha_{k} X_{k}\right)}\right)}{\frac{1}{1+\exp \left(\alpha_{0}+\alpha_{1} X_{1}+\alpha_{2} X_{2}+\ldots+\alpha_{k} X_{k}\right)}}\right\}$

for $0 \leq \operatorname{Pr}\left(X_{k}\right) \leq 1$

Therefore, the logarithmically transformed logit regression model, equation [06] can be rewritten as a linear combination of the explanatory variables as follows [07]:

$$
\begin{gathered}
\text { Logit }=\operatorname{In}\left(\frac{\operatorname{Pr}\left(X_{k}\right)}{1-\operatorname{Pr}\left(X_{k}\right)}\right)=\alpha_{0 i}+\alpha_{i 1} \text { Age }_{i 1}+\alpha_{i 2} \text { ChangesTreeFarms }_{i 2}{ }^{+} \\
\alpha_{i 3} \text { ChangesForestCoverage }_{i 3}+\alpha_{i 4} \text { ChangesTreeSpecies }_{i 4}+\alpha_{i 5} \text { ChangesRainFall }_{i 5}+ \\
\alpha_{i 6} \text { ChangesTemperature }_{i 6}+\alpha_{i 7} \text { Camp }_{i 7}
\end{gathered}
$$


Note: The diagnostic tests indicated that there were no multi-colinearity, endogeneity, and heteroscedasceticity problems. In addition, the error term was normally distributed

\section{Results and analysis}

\subsection{Descriptive statistical analysis}

The average age of the sample respondents was 44.8 years with the lowest age being 17 and the highest age was 77 years. Table 2 reported the descriptive statistical analysis of the characteristics affecting the socio-environmental impact of the host community due to the existence of refugee populations in the study areas. The descriptive statistical analysis indicated that $96.35 \%$ of the sample respondents replied that there were changes of tree species on the community farms while the remaining $3.65 \%$ replied to the alternative. Similarly, about $96.88 \%$ of the sample respondents indicated significant changes in community forest coverage but only $3.13 \%$ of them confirmed that there were no changes in the community forest coverage following the introduction of the refugees.

Table 2. Descriptive analysis of the socio-environmental characteristics on the refugee settlement areas (Source: survey computation)

\begin{tabular}{|l|c|c|c|c|c|c|c|c|c|c|}
\hline \multirow{2}{*}{ Kebelle/Camp } & \multicolumn{2}{|c|}{$\begin{array}{c}\text { Changes } \\
\text { tree types on } \\
\text { farm }\end{array}$} & \multicolumn{2}{c|}{$\begin{array}{c}\text { Change on } \\
\text { forest coverage }\end{array}$} & \multicolumn{2}{c|}{$\begin{array}{c}\text { Change on } \\
\text { tree species }\end{array}$} & \multicolumn{2}{c|}{$\begin{array}{c}\text { Perceived } \\
\text { changes on } \\
\text { rainfall }\end{array}$} & $\begin{array}{c}\text { Perceived } \\
\text { changes on } \\
\text { temperature }\end{array}$ \\
\cline { 2 - 12 } & No & Yes & No & Yes & No & Yes & No & Yes & No & Yes \\
\hline Hitsats/Hitsats & 1.04 & 0.21 & 2.6 & 8.65 & 0.5 & 30.73 & 2.6 & 8.7 & 0.00 & 31.25 \\
\hline Maykuhili/Shimelba & 1.04 & 34.90 & 0.52 & 35.42 & 0.00 & 35.94 & 0.0 & 35.94 & 1.04 & 34.9 \\
\hline Wuhdet/Adiharush & 1.56 & 31.25 & 0.00 & 32.81 & 0.52 & 32.29 & 2.60 & 30.21 & 0.52 & 32.29 \\
\hline Total & 3.65 & 96.35 & 3.13 & 96.9 & 1.04 & 99 & 5.21 & 94.79 & 1.56 & 98.44 \\
\hline
\end{tabular}

Values are expressed in terms of percentage

The descriptive analysis revealed that the $98.96 \%$ of the sample respondents replied that the changes in tree species in the community were observed significantly over periods. Moreover, $94.79 \%$ of the respondents also perceived that there were rainfall changes from the sampled households of the host community, while $5.21 \%$ replied the other way. Most importantly, about $98.44 \%$ of the sample respondents also perceived a significant change in temperature throughout the study area with almost similar response rates across all the study area.

\subsection{Empirical findings}

Table 3 reported the results for socioenvironmental impacts of refugees on the host communities based on a binary logistic regression analysis. The first and second columns of the table contain the lists of the variables and estimated regression coefficients of these variables, respectively. A positive value of the estimated regression coefficients indicates a positive relationship between the dependent and independent variables, while a negative value indicates the opposite. For ease of interpretation, the results of the logistic regression analysis were explained in terms of odds ratios displayed in the third column of Table 3. A value of odds ratio greater than unity (Odds ratio $>1$ ) indicates the increased likelihood of the host community being affected negatively by the socio-environmental determinant factors while a value of odds ratio less than unity (Odds ratio $<1$ ) indicates the opposite. As indicated in Table 3, the logistic regression analysis indicated that the change in the forest coverage (changes in forest coverage) is strongly and positively associated with the refugees' impact on host communities. Thus, the refugees' impact on the host community increased by a factor of 1.029 while keeping all other factors constant in the model. Moreover, the change in tree species (changes in tree species) as a determinant factor of the impact of refugee populations on the host community was found to negatively affect the host community. The odds of being the refugees' impact on the host community increased by a factor of 10 with changes in tree species of the host community while keeping the effects of all other determinants in the model constant.

The results further revealed that the perceived changes in rainfall (changes in rainfall) were among the key determinant factors of the impact of refugee populations on the host communities. 
Thus, keeping all other factors constant, findings revealed that the changes in rainfall affected both positively and strongly the probability of being the refugee's impact on the host communities, with the changes of being the impact of refugees' on the host communities increased by a factor of 3.11 .

The perceived changes in temperature due to the existence of refugees in the host community (Changes in Temperature) was another significant determinant factor which positively affected the probability of the impacts of the refugee populations on the host community. Therefore, the impact of refugees' on the host community showed significant changes on temperature, the predicted odds of being the impact increased by a factor of 1.012 while keeping the effects of all other determinants in the model constant. Furthermore, the camp of the refugees was considered as a separate categorical independent variable and was found to affect the independent variable. Compared to Hitsats refugee settlement area Maykuhili host community was significantly affected, with the odds of being the impact of the refugee populations on host community increased by a factor of 1.012 , while keeping the effects of all other determinants in the model constant. To the contrary, Wuhdet refugee settlement area was less affected than Hitsat, while keeping all other determinant factors constant. Maykuhili refugee settlement area was the highest affected area followed by the Hitsats refugee settlement area compared with the Wuhdet refugee settlement area.

Table 3. Socio-environmental impact of refugee populations on hosting communities: Estimates of a logistic regression analysis (Source: survey computation)

\begin{tabular}{|l|r|r|r|r|r|r|}
\hline \multicolumn{1}{|c|}{ Variables } & Coefficient & Odds ratio & \multicolumn{1}{c|}{$\begin{array}{c}\text { Robust } \\
\text { Standard } \\
\text { Error }\end{array}$} & P-value & \multicolumn{2}{c|}{$\begin{array}{c}\text { [95\% Confidence } \\
\text { interval] }\end{array}$} \\
\hline Age & 0.305249 & 1.357 & .37305 & 0.413 & -.4259046 & 1.036404 \\
\hline $\begin{array}{l}\text { Changes tree farms } \\
(1=\text { Yes, used as a reference) }\end{array}$ & -0.194765 & .8230 & .32872 & 0.554 & -.8390529 & .4495234 \\
\hline $\begin{array}{l}\text { Changes forest coverage } \\
(1=\text { Yes, used as a reference) }\end{array}$ & $0.028480^{* *}$ & 1.029 & .01154 & 0.014 & .0058547 & .0511048 \\
\hline Changes tree species & $2.2851^{*}$ & 9.834 & 1.2004 & 0.063 & 1.441694 & 4.561186 \\
\hline $\begin{array}{l}\text { Changes rainfall } \\
(1=\text { Yes, used as a reference) }\end{array}$ & $1.13425^{* * *}$ & 3.109 & .42084 & 0.007 & .3094194 & 1.959077 \\
\hline Changes in temperature & $0.011625^{*}$ & 1.012 & .00642 & 0.070 & .0242149 & .0009657 \\
\hline Hisats/Hitsats (1= used as a reference) & & & & & & \\
\hline Wuhdet/Adiharush & -0.082419 & 0.764 & .05514 & 0.139 & -.1923859 & .027547 \\
\hline Maykuhili/Shemelba & 3.524339 & 4.125 & .81716 & 0.000 & 1.894605 & 5.154072 \\
\hline -cons & 49.52261 & 6.431 & & 0.000 & 36.67592 & 62.36931 \\
\hline Model summary & Statistics & p-vale & & & & \\
\hline Model Chi-squared & 29.23 & 0.0000 & & & & \\
\hline Pseudo R-squared & 0.2735 & & & & & \\
\hline Number of observations. & & & & & \\
\hline
\end{tabular}

Note: The asterisks denote the level of significance ${ }^{* * *} \mathrm{p}<0.01,{ }^{* *} \mathrm{p}<0.05$, and ${ }^{*} \mathrm{p}<0$

\section{Discussion}

During the study period, the impact of refugee populations has been assessed in depth on refugee their host communities. The increase in population in the area was ultimately linked to the environment and to limits on natural resources, such as water, land, forests, tree species and basic requirements, such as energy came into sharper focus. The environmental impacts of refugee settlers on host communities have been evident. Notably, the study emphasizes the socio-environmental impact of host communities of these three refugee settlement areas. As a result, changes have been observed after the establishment of refugee camps in the study areas. Issues have been raised by the host community emphasising that the close proximity of the refugee camps to the forest area has been a key contributing factor to resource degradation. The increased number of displaced population being settled in an area is the most common reasons for deforestation to make houses for the people to live in, and to use wood as a fuel 
(MltTal \& GuPTA MitTal, 2013). Furthermore, natural resource degradation amalgamated with the existance of refugees and their camps was noted as one of the negative impacts on the host community (TAYLOR ET AL, 2016b). As the livelihood of the host community depends on agriculture, human interference on the natural environment brought about a significant impact on the area. Environmental impacts are only one of the many factors that influence and shape the relationship between the refugees and their hosts: the combination of factors differs greatly in each refugee situation (OECD, 2017). As the government of Ethiopia has maintained open boarders for refugees seeking protection in the country, the environmental security has been neglected in order to adopt sustainable practices. In Tigray, particularly the north western part of the region, where traditional agriculture is practiced, land is heavily exploited (TYHRA \& KWADWO, 2011). The findings have shown that the presence of large number of refugees within the time period of settlement in the area has been associated with environmental impacts particularly on the natural resources of forest coverage with a decline in the local races of tree species. Deforestation and depletion of resources are the most frequent environmental problems in the Western Tanzania refugee settlement area: where the rate of deforestation is much higher than the national average. Research indicates, the direct effects on the forest cover caused by the circumstances of displacement of an increased number of people with high deforestation and environmental degradation being serious problems in and around refugee settlement areas (MILAN ET AL., 2016). The devastation in forest cover and the perceived changes in temperature and rainfall were positively associated with the increased refugee populations on the host community. Certainly, in an area where there is scarcity of land and natural resources, the existence of large number of refugees increases the competition for resources in the host communities (REED, 2015).

More precisely, the findings of this study have shown that the presence of refugee populations in the settlement areas of May kuhili, Wuhdeth and Hitsats has brought substantial changes in the environment. They also indicate that there are socio-environmental impacts on the hosting communities. This time it has become much serious that the existence of refugee camps increases social conflicts and economic disaster (UN, 2018). Such situations made us understand that no one should undermine the possible impacts of a refugee population on its host community (UNPD, 2017). Refugees in the areas use forests to satisfy their timber and fire wood requirements. Significantly, in all refugee settlement areas the change in tree species significantly affected the host communities. (Chauvet ET AL., 2016) noted that it is widely accepted that the influx of refugees can have considerable impacts on natural resources and socio-economic aspects. According to the results obtained from the socio-environmental analysis, the influx of refugee populations has caused a sudden decline in tree species on farms due to an increased demand for the scarce natural resource used for shelter and as a source of energy. The pressing environmental changes of many refugee settlement areas have been manifested through a depletion of forest trees and shrubs (OECD, 2017).

Similarly, among the socio-environmental impacts experienced by the host community after the refugee influxes, a decline in the forest coverage has been more significant in terms of resource depletion and the livelihood of the host community as they depend on agriculture for their survival. In this case, high resource competition contributes to an increased community level conflicts and an instability which returns less in the interactions that can further potentially escalate into local insecurity (TAYLOR ET AL., 2016b). As there is no access to alternative energy sources and other necessities, the refugee populations and host community members depend on the forests/trees for different uses. The close proximity of forests to refugees and the host communities as well, are contributing factor to encroach on forest cover areas, primarily to use the wood as energy source or to use for construction (GUNNING, 2014). Loss of tree species has posed serious significant problems in terms of the sustainability of biodiversity. These environmental impacts can be more serious as losses of indigenous and locally adopted species disappear forever. Thus, better knowledge about refugee populations can assist in planning and implementing projects that may lessen livelihood conflicts (LEAH, 2008).

Based on the views of the respondents there are perceived changes in rainfall and temperature along with changes in the forest and tree coverage in the area. The impact of a high rate of forest and tree losses in the areas according to respondents. $(\mathrm{FAO}, 2018)$ in his analysis, mentioned three reasons why environmental degradation is not given a high priority in refugee projects: the international organizations responsible for refugee care have no comprehensive long-term environmental policy regarding emergency relief and rehabilitation; the views of both the local 
people and refugees concerning environmental degradation are neglected in the design of remedial programs. Therefore the policy choices for resource allocations to refugees should never be treated apart from the interest of the local communities. The host community governments are more criticized on the environmental trends that are widely believed to be that the least attention on environmental degradation and natural resources depletion (GRINDHEIM, 2013). The hosting community and the refugee populations practiced illegal cutting of live trees rather than travelling long distances to find dead wood, which further contributed to the degradation (UNEP, 2005). It is clear that, the influx of refugees with a sudden occupation of new populations in the study area brought about a significant impact on the host community with a sudden decline in the natural resources and this has had implications for the socio-environmental issues in the area.

\section{Conclusions}

As a result of high population pressure following refugee settlements in the study areas, the socioenvironmental situation has been significantly changed. The study clearly demonstrates this in terms of the current and future access to an agricultural environment. Modification of the natural vegetation usually leads to uncertainties in the sustainability of the host community of rural dwellers where the refugee population has settled. Major changes have been observed in all the independent variables which were strongly and positively associated with the socio-environmental changes in host communities. The overall findings revealed that the massive presence of the refugees has negative implications and perceptions. Environmental impacts on the host community have had a significant impact as they depend on land for pursuing their livelihood. The social interactions between the host community and the refugee populations have also been hampered due to competition for environmental resources. Because livestock production in the study areas is based on an open, or free grazing system, the decline in tree species which insures feed for their livestock has been a source of conflict in the study areas.

The existing situation indicated that there are major socio-environmental factors that affect the livelihood of the host communities. Based on the results of this study, the concerned bodies, such as government and non-governmental organizations should address these host community problems and the issues around the refugee populations in a holistic manner. In order to minimize the overall challenges on the environment, an immediate intervention of local, national, international and host governments, with holistic environmental mitigation measures needs to move forward.

\section{Acknowledgement}

We would like to acknowledge Aksum University for giving us access to research this current regional issue and the financial support to carry out the work.

\section{References}

Alix-Garcia J., Saah D. 2010. The Effect of Refugee Inflows on host Communities: Evidence from Tanzania. The World Bank Economic Review, 24, 1: 148-170.

Alloush M., Taylor J.E., Gupta A., Valdes R.I.R., GonzalezEstrada E. 2017. 2017. Economic life in refugee camps. World Development, 95: 334-347.

Beine M., Bertoli S., Fernandes-Huertas Morga J. 2016. A practitioners' guide to gravity models of international migration. The World Economy, 39. 4: 496-512.

Bilgili Ö., Loschmann C. 2018. Refugees and host communities in the Rwandan labour market. Forced Migration Review, 58: 22-23.

Birhanu S., Desta T. 2018. The Socio-economic Impacts of Refugees on the neighbouring Countries: The Case of Shrkole Refugee Camp, Western Ethiopia.

Blundell A.G., Farah D., Harwell E 2011. Forests, Fragility and Conflict. World Bank, Washington, DC

Chauvet L., Gubert F., Mesplé-Somps S. 2016. Do migrants adopt new political attitudes from abroad? Evidence using a multi-sited exit-poll survey during the 2013 Malian elections. Comparative Migration Studies, 4(19).

Crush J., Dodson B., Williams V., Tevera D. 2017. Harnessing Migration for Inclusive Growth and Development in Southern Africa: Special Report. Southern African Migration Programme. Waterloo, Canada.

de Haas H. 2012. The migration and development pendulum: a critical view on research and policy. International Migration, 50(3): 8-25.

Evans A. 2010. Resource Scarcity, Climate Change and the Risk of Violent Conflict. World Development Report Background Paper, World Bank, Washington.

FAO. 2018. Managing Forests in Displacement Settings: Guidance on the Use of Planted and Natural Forests to Supply Forest Products and Build Resilience in Displaced and Host Communities. Rome, FAO and UNHCR. www.fao.org/3/I8309EN/i8309en.pdf.

Gomez M.P, Christensen A. 2010. The impact of refugees on neighboring countries: A Development challenge. World Bank. Washington, D.C.

Grindheim K.A. 2013. Exploring the impacts of refugee camps on host community. A case of Kakuma host community Kenya (Master's Thesis). University of Agder.

Gunning, R. 2014. The current state of sustainable energy provision for displaced populations: An analysis. The Royal Institute of International Affairs Chatham Hous, London.

Hosmer D.W., Lemesbow S. 2000. Applied logistic regression (Second Edition).Wiley. New York.

IDMC. 2014. Global Estimates 2014: People Displaced by Disasters. Geneva: IDMC. Accessible at: http://www. internaldisplacement.org/assets/publications/2014/20 1409-global-estimates2.pdf 
Kirui P., Mwaruvie J. 2012. The Dilemma of Hosting Refugees: A focus on the insecurity in North-Eastern Kenya. International Journal of Business and Social Science, 3, 8: 161-171.

Leah B. 2008. The impact of environmental degradation on refugee-host relations: a case study from Tanzania. New Issues in Refugee Research, Research Paper no. 151: 1-19.

Milan A., Oakes R., Campbell J. 2016. Tuvalu: climate change and migration - relationships between household vulnerability, human mobility and climate change. Report No. 18. Bonn: United Nations University, Institute for Environment and Human Security (UNU-EHS http://collections.unu.edu/view/UNU:5856.

Mlttal R., Gupta Mittal Ch.. 2013. Impact of population explosion on Environment. WeSchool "Knowledge Builder", The National Journal, 1, 1: 1-5.

NRC. 2014. Ethiopian fact sheet. Norwegian refugee Council, Ethiopia.

OECD. 2017. Responding to Refugee Crises in Developing Countries: What can we learn from Evaluations? OECD Publishing, Paris, http://dx.doi.org/10.1787/22220518.

Omata N., Weaver N. 2015. Assessing economic impacts of hosting refugees. Refugee Studies Center, University of Oxford.

Reed R.K. 2015. Environmental destruction, guaraní refugees, and indigenous identity in Urban Paraguay. In: Wodd D.C. (ed.) Climate change, culture, and economics: anthropological investigations. Emerald Group Publishing Limited, Bingley, UK: 263-292.

Taylor J.E., Filipski M.J., Alloush M., Gupta A., Valdes R.I.R., Gonzalez-Estrada E. 2016a. Economic impacts of refugees. Proceedings of the National Academy of Sciences of the USA, 113, 27: 7449-7453.
Taylor J.E., Zhu H., Gupta A., Filipski M., Valli J., Gonzalez E. 2016b. Economic Impact of Refugee Settlements in Uganda. University of California Davies/IFPRI/World Food Programme.

Tyhra C.K., Kwadwo A.O. 2011. Responding to land degradation in the highlands of Tigray, northern Ethiopia. International Food Policy Research, Discussion Paper, 01142. Eastern and Southern Africa Regional Office.

UN. 2018. Migration for Structural Transformation. Economic Development in Africa. United Nations Conference on Trade and Development.

UNEP. 2005. Impacts of Refugees and Internally Displaced Persons on the Environment in Tanzania. www.unep.org /depi/programmes/emergencies.html, Accessed date: August 2006.

UNEP. 2011. Decoupling Natural Resource Use and Environmental Impacts from Economic Growth. UNEP, Paris.

UNHCR. 2003. Global Refugee Trends. Overview. www.unhcr.org /unhorstats/

UNHCR. 2011. Global Trends. www.unhcr.org/gr11/index.xml

UNPD. 2017. Trends in International migrant stock: The 2017 revision. Department of Economics and Social Affairs (United Nations database, POP/DB/MIG/Stock/Rev.2017).

Wilson C. 2014. Spectral analysis of civil conflict-induced forced migration on land-use/land-cover change: the case of a primate and lower-ranked cities in sierra leone Interntional Journal Remote Sensing, 35: 1094-125.

Wooldridge J.M. 2002. Econometric Analysis of Cross section and Panel Data. The MIT press: Cambridge Relief to Development Society. 